\title{
SISTEM PENGOLAHAN DATA JEMAAT GKJ KISMOREJO BERBASIS WEB
}

\author{
Oktavianus Bima Aji Setiawan¹, S. M. Santi Winarsih ${ }^{2}$ \\ 1,2 Prodi Teknik Informatika \\ Universitas Kristen Surakarta \\ e-mail: ${ }^{1}$ oktavianusbima@gmail.com, ${ }^{2}$ kshervida@yahoo.co.id \\ Jl. RW Monginsidi No. 36-38, Surakarta 57143
}

\begin{abstract}
The problems faced by GKJ Kismorejo currently are still using Microsoft Office Word and in disseminating information such as data on congregations that are still active or not active, information on congregations who died, congregational marriages, and other congregational data through paper-based congregations. To print church messages and reports requires a large amount of operational funds. In addition, data collection and storage still have shortcomings, including recording some data in books, difficulties in processing large amounts of data and storing it in only one place. For this reason, the authors raise the background of the problems that occur, the authors are interested in conducting research with the title Designing Data Processing Systems for Web-Based GKJ Kismorejo Congregation. The purpose of this research is to design and produce a data processing system for the church. Using this system can facilitate data processing in the church.
\end{abstract}

Keywords: web, data processing, operational

\begin{abstract}
Abstrak
Permasalahan yang dihadapi GKJ Kismorejo saat ini masih menggunakan Microsoft Office Word dan dalam penyebaran informasi seperti data jemaat yang masih aktif atau sudah tidak aktif, informasi jemaat meninggal dunia, pernikahaan jemaat, dan data jemaat lainnya melalui warta jemaat yang berbasis kertas. Untuk mencetak warta jemaat dan laporan membutuhkan dana operasional cukup besar. Selain itu pengumpulan dan penyimpanan data masih terdapat kekurangan di antaranya mencatat beberapa data pada buku, kesulitan untuk mengolah data dalam jumlah besar dan tersimpan hanya pada satu tempat. Untuk itu penulis mengangkat latar belakang dari permasalahan yang terjadi, penulis tertarik untuk melakukan penelitian dengan judul Perancangan Sistem Pengolahan Data Kegiatan Jemaat GKJ Kismorejo Berbasis Web. Tujuan penelitian ini untuk merancang dan menghasilkan suatu sistem pengolahan data untuk gereja. Dengan menggunakan sistem ini dapat memudahkan dalam pengolahan data dalam gereja.
\end{abstract}

Kata kunci: web, pengolahan data,operasional 


\section{PENDAHULUAN}

Sistem pengolahan data merupakan suatu cara yang sangat diperlukan untuk gereja, dan pentingnya data jemaat untuk gereja. Sistem tersebut menjadikan penyimpanan data, penambahan, pengubahan, dan hingga pelaporan menjadi terintegrasi dengan baik, sehingga dapat membantu bagian-bagian untuk saling bertukar informasi dan mengambil keputusan dengan cepat. Permasalahan yang dihadapi GKJ Kismorejo saat ini masih menggunakan Microsoft Office Word dan dalam penyebaran informasi seperti data jemaat yang masih aktif atau sudah tidak aktif, informasi jemaat meninggal dunia, pernikahaan jemaat, dan data jemaat lainnya melalui warta jemaat yang berbasis kertas dan majalah dinding. Untuk mencetak warta jemaat dan laporan membutuhkan dana operasional cukup besar. Penelitian sebelumnya tentang Perancangan Sistem Pengolahan Data Jemaat Berbasis Web ini sudah pernah dilakukan di Gereja GKPI Kota Jambi. (Dame Christine Sagala, 2018)

Selain itu pengumpulan dan penyimpanan data masih terdapat kekurangan di antaranya mencatat beberapa data pada buku, kesulitan untuk mengolah data dalam jumlah besar dan tersimpan hanya pada satu tempat. Untuk mengatasi permasalahan tersebut maka diperlukan suatu sistem yaitu Sistem Pengolahan Data Jemaat GKJ Kismorejo Berbasis Web. Tujuan penelitian ini untuk merancang dan menghasilkan suatu sistem pengolahan data untuk gereja. Dengan menggunakan sistem ini dapat memudahkan dalam pengolahan data dalam gereja.

\section{METODE PENELITIAN}

\subsection{Tahapan Review}

a. Tempat Penelitian

GKJ Kismorejo beralamatkan Jl Raya Solo - Karanganyar KM. 10.3 Jaten Karanganyar.

b. Teknik Pengumpulan Data (Sudaryono, 2015)

Untuk memperoleh data yang diperlukan guna mendukung pelaksanaan penelitian

Ini digunakan beberapa teknik pengumpulan data antara lain sebagai berikut,

- Observasi

Suatu teknik pengumpulan data dengan cara pengamatan langsung terhadap

objek yang ada di lapangan.

- Dokumentasi

Penulis mengamati dokumen yang berhubungan dengan informasi informasi

mengenai jurusan

- Wawancara

Wawancara dilakukan di lokasi penelitian dengan petugas Gereja setempat.

c. Langkah / Alur Penelitian

- Mengobservasi segala data yang ada di GKJ Kismorejo.

- Memilih sistem pengolahan data yang akan digunakan di web,dan sesuai yang diharapkan gereja.

- Membuat skema sitem pengolahan data jemaat sesuai yang di harapkan. 
- Merancang bagian sistem pengolahan data jemaat di web.

- Mengimplementasikan data ke sistem pengolahan data di web.

- Meningkatan sistem pengolahan data jemaat website bila diperlukan.

\section{2. Pengacuan Pustaka}

\section{a. Website}

Website atau situs juga dapat diartikan sebagai kumpulan halaman yang menampilkan informasi data teks, data gambar diam atau gerak, data animasi, suara, video dan atau gabungan semuanya, baik yang berupa statis maupun dinamis yang membentuk suatu rangkaian bangunan yang saling terkait dimana masing-masing dihubungkan dengan jaringan-jaringan. (F. N. Putranto, 2017)

\section{b. Hypertext Prepcessor (PHP)}

PHP adalah suatu bahasa open source yang digunakan secara luas terutama untuk pengembangan web dan dapat disimpan dalam bentuk HTML. Untuk menghasilakan sebuah HTML, script yang ditulis menggunakan PHP mempunyai perintah yang lebih singkat dibandingkan bahasa pemrograman lain seperti perl atau C. Hanya perlu memasukkan kode untuk melakukan sesuatu (misalnya menulis suatu kalimat) diantara tag awal dan tag akhir PHP. (Handayani, 2016)

\section{c. MySQL}

MySQL adalah sebuah program database server yang mampu menerima dan mengirimkan datanya dengan sangat cepat, multiuser serta menggunakan perintah standar SQL (Structured Query Language). My SQL merupakan sebuah database server yang free, artinya kita bebas menggunakan database ini untuk keperluan pribadi atau usaha tanpa harus membeli atau membayar lisensinya. (Arief, 2011)

\section{d. Web Browser}

Web browser atau yang lebih dikenal browser adalah suatu program atau aplikasi untuk mencari sebuah informasi dari suatu halaman web/blog. Browser yang sering digunakan oleh para pengguna internet yaitu Internet Explorer, Mozila Firefox, Opera, Google Chrome, Netscape Navigator, Mozaic, Avant Browser dan lain-lain. (Yuhefizar, 2013)

\section{HASIL DAN PEMBAHASAN}

Implementasi Sistem merupakan hasil dari sebuah program yang telah dibuat dan sebgai gambaran bagaimana untuk cara menggunakannya. Dibawah ini merupakan hasil implementasi dari "Sistem Pengolahan Data Jemaat GKJ Kismorejo" dilengkapi dengan Gambar masingmasing halaman dari sitem pengolahan data ini.

1. Flowchart Sistem (Kadir, 2014)

Flowchart web pengelohan data jemaat GKJ Kismorejo dapat dilihat pada Gambar 1. 


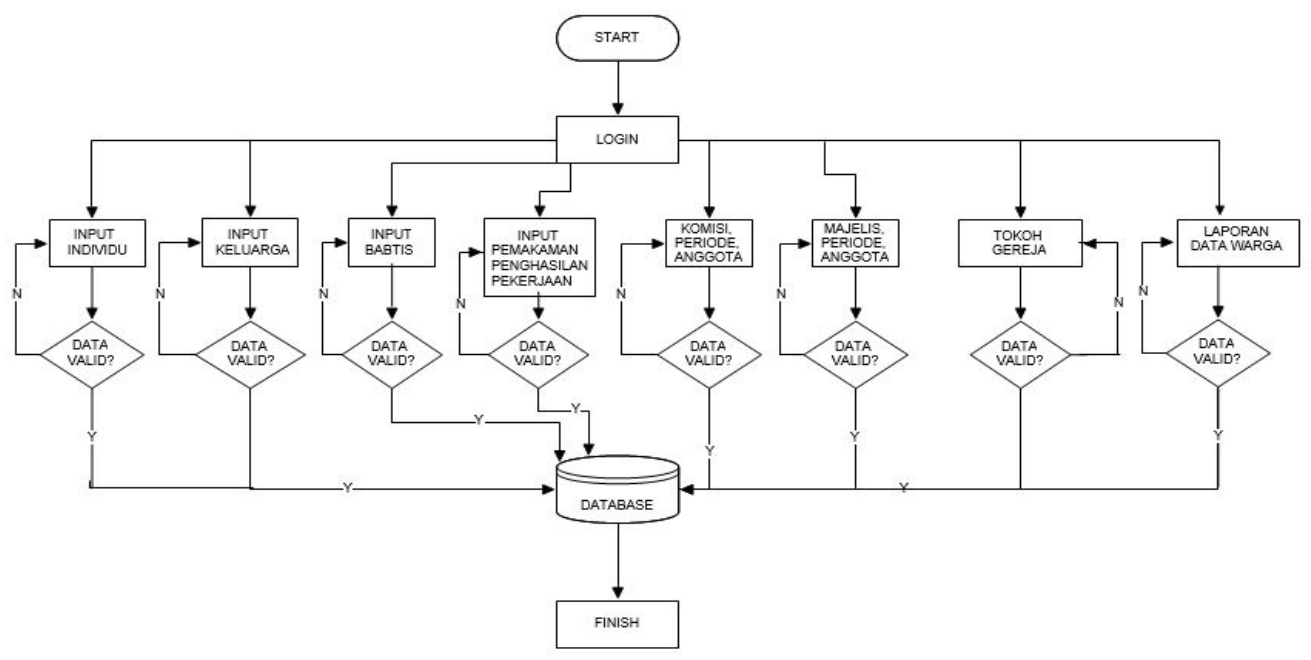

Gambar.1. Perancagan Flowchart Sistem

2. Data Flow Diagram (DFD) / Use Case Diagram (Pressman, 2002) Gambar untuk perancangan DFD level 0 dan level 1 dapat dilihat pada gambar 2 dan gambar 3 berikut ini:

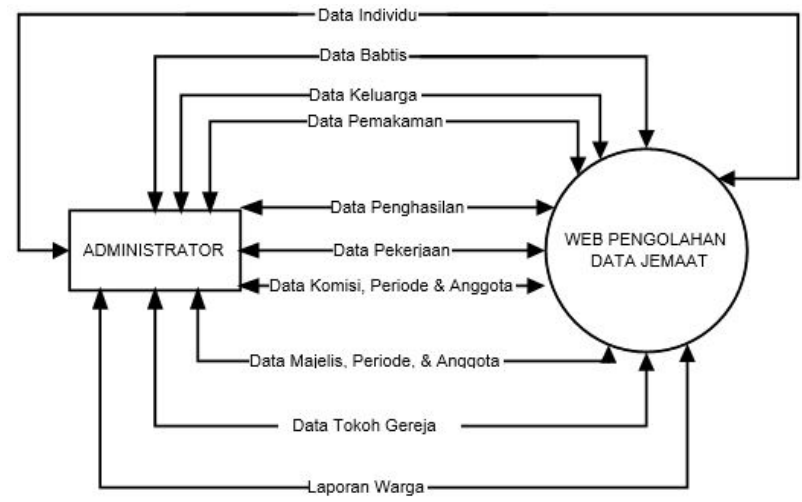

Gambar.2. Perancangan DFD Level 0 


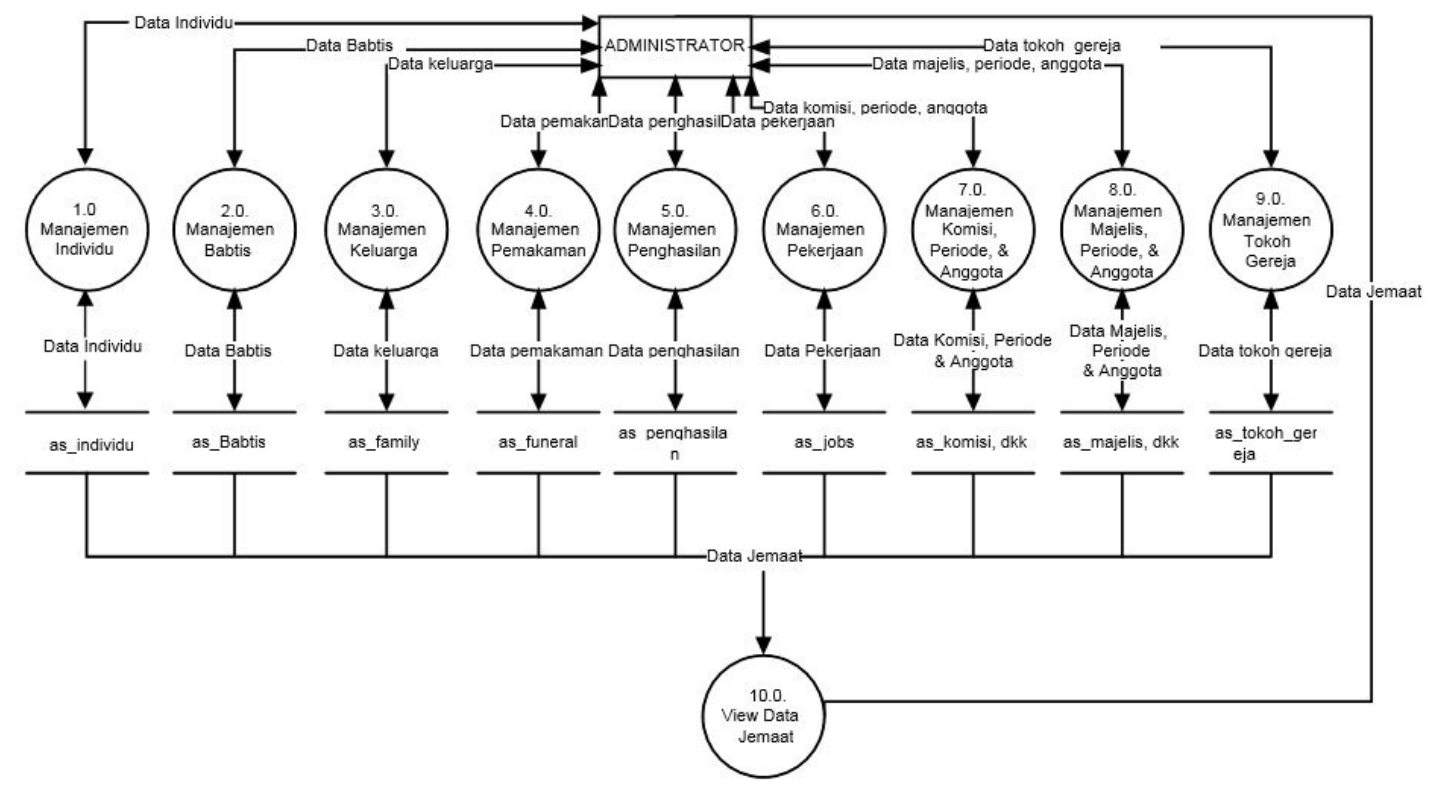

Gambar.3. Perancangan DFD Level 1

\section{Halaman Login}

Halaman Login terdapat form untuk login admin gereja untuk masuk ke halaman utama pada gambar 4.

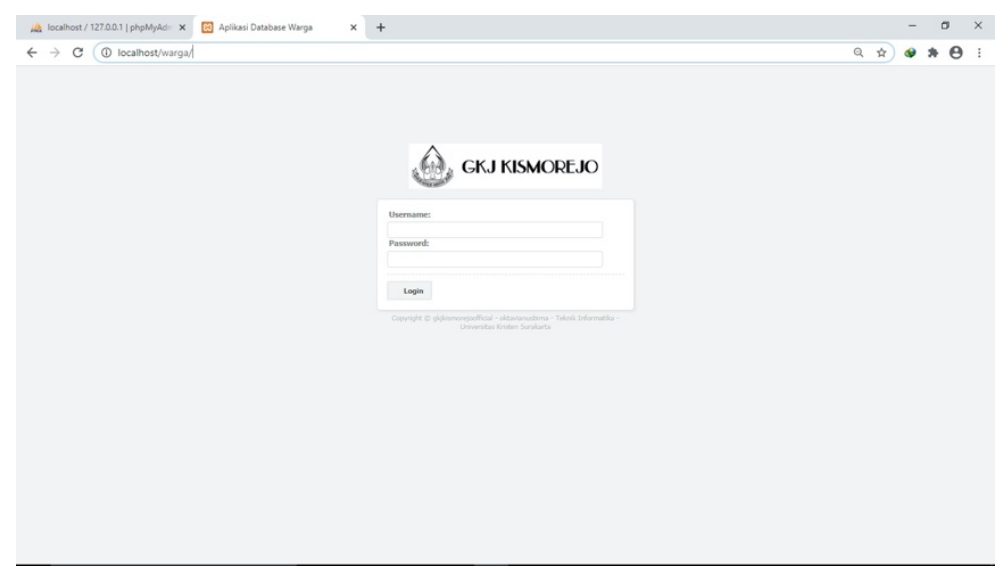

Gambar.4. Halaman Login

\section{Halaman Utama}

Halaman utama terdapat berbagai pilihan halaman menu proses pengolahan data jemaat. Terdapat master data terdapat proses data pemakaman, data pekerjaan, dan data penghasilan. Kartu keluarga terdapat proses data individu, dan data keluarga. Manajemen babtis terdapat proses data babtis. Manajemen komisi terdapat proses data periode komisi, komisi, dan anggota komisi. Manajemen majelis terdapat proses data periode majelis, majelis, dan anggota majelis. Manajemen staff terdapat proses data 
staff. Halaman Tokoh gereja terdapat proses data tokoh gereja. Laporan data warga terdapat proses pelaporan data berdasarkan kelompok umur, berdasarkan gender, jemaat masuk dan keluar, terlihat pada gambar 5 .

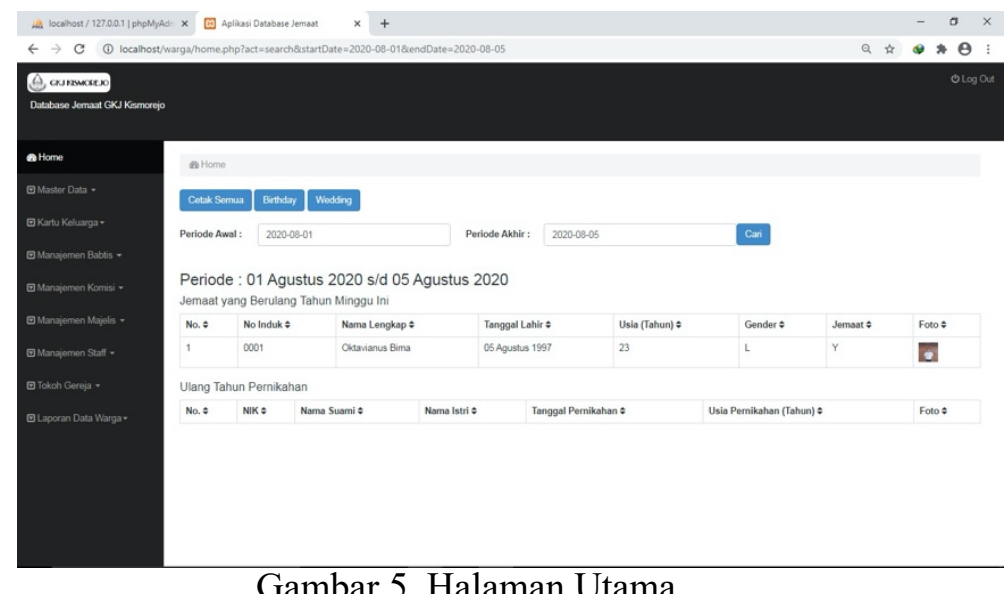

\section{KESIMPULAN}

Berdasarkan dari hasil pengujian dan analisis program, maka dapat disimpulkan sebagai berikut : Sistem Aplikasi Website ini dapat membantu pekerjaan staff gereja dalam pengolahan data jemaat, sehingga dngan adanya Sistem Aplikasi Webiste ini pekerjaan staff gereja menjadi efektif dan efisien serta mempermudah mencari informasi tentang data jemaat di gereja.Dengan adanya Sistem Aplikasi Webiste ini juga mempermudah pelaporan data jemaat gereja. Sehingga apabila diperlukan pelaporan bisa segera disajikan denga baik dan tepat waktu.

\section{Referensi}

Arief, M. R. (2011). Pemrograman Web Dinamis Menggunakan PHP Dan MySQL. Yogyakarta: Andi Offset.

Dame Christine Sagala, A. S. (2018). Perancangan Sistem Pengolahan Data Jemaat Berbasis Web pada Gereja Gkpi Kota Jambi. Jurnal V-Tech, 14-24.

F. N. Putranto, Y. Y. (2017). , "Rancang BAngun Sistem Informasi Rekam Medis Klinik Berbasis Web (Studi Kasus : Klinik Utama Meditama Semarang). Jurnal Inform. UPGRIS, Vol.3, no. 2, 105-115.

Handayani, G. F. (2016). , "PERANCANGAN SISTEM INFORMASI REKAM MEDIS BERBASIS WEB (STUDI KASUS DI KLINIK BERSALIN SRIATI KOTA SUNGAI PENUH - JAMBI. Jurnal Teknologi Informatika dan Komputer, Vol 2(2), 226-235. doi:doi: http://dx.doi.org/10.36002/jutik.v2i2.148 
Kadir, A. (2014). Pengenalan Sistem Informasi. Yogyakarta: CV Andi Offset.

Pressman, R. S. (2002). Rekayasa Perangkat Lunak. Yogyakarta: CV. Andi Offset.

Sudaryono, M. R. (2015). Metodologi Riset di Bidang IT. Yogyakarta: CV Andi Offset.

Yuhefizar. (2013). Cara Mudah \& Murah Membangun \& Mengelola Website. Yogyakarta: Graha Ilmu. 